\title{
The Dimmable Single-stage Asymmetrical LLC Resonant LED Driver with Low Voltage Stress Across Switching Devices
}

\author{
Seong-Ju Kim*, Young-Seok Kim ${ }^{\dagger}$, Choon-Taek Kim*, Joon-Min Lee* and Jae-Du La**
}

\begin{abstract}
In the LED lighting industry, the dimming function in the LED lamp is required by demands of many consumers. To drive this LED lighting, various types of power converters have been applied. Among them, an LLC resonant converter could be applied for high power LED lighting because of its high efficiency and high power density, etc. The function of power factor correction (PFC) might be added to it. In this paper, a dimmable single-stage asymmetrical LLC resonant converter is proposed. The proposed converter performs both input-current harmonics reduction and PFC using the discontinuous conduction mode (DCM). Also, the lower voltage stress across switching devices as well as the zero voltage switching (ZVS) in switching devices is realized by the proposed topology. It can reduce cost and has high efficiency of the driver. In addition, the regulation of the output power by variable switching frequency can vary the brightness of a light. In the proposed converter, one of the attractive advantages doesn't need any extra control circuits for the dimming function. To verify the performance of the proposed converter, simulation and experimental results from a $300 \mathrm{~W}$ prototype are provided.
\end{abstract}

Keywords: Asymmetrical, LLC resonant converter, Low voltage stress, Single-stage PFC, LED, DCM, Dimming method, Frequency control

\section{Introduction}

An LED lamp has been newly recognized as a new lighting system due to the performance improvement of LED. Various driving techniques for the LED lamp have been rapidly developed. Furthermore, the LED lamp as a next generation lighting system offers many advantages to lighting system designers: high efficiency, long life, design flexibility, weight reduction, modularity, ecologically friendliness, etc.

In an LED lighting system, an LED driver is one of the greatest concerns. A constant DC voltage or DC current is required to operate an LED lamp. A proper driver should be chosen for diverse application of the LED. Thus, the choice and implementation of the LED driver is very important for the achievement of a satisfactory performance level.

In these applications, power availability and power density are of paramount importance, and developments appear to be more advanced and mature than those in the lighting system industry. Furthermore, to vary the brightness of an LED lamp and satisfy many consumers' demands, a wide range of studies for power converters with the

$\dagger$ Corresponding Author: Dept. of Electrical Engineering at Inha University in Incheon, Korea. (youngsk@inha.ac.kr)

* Dept. of Electrical Engineering at Inha University in Incheon, Korea. (billbosa@naver.com, ctkim1967@hanmail.net, joonminlee82@ gmail.com)

** Department of Electrical Information at Inha Technical College in Incheon, Korea. (jenadu@gmail.com)

Received: January 20, 2014; Accepted: May 12, 2015 function of dimming control have been carried out [1-4].

In the front-end stage, conventional power converters with diode rectifiers use a bulk capacitor and result in non-sinusoidal line current from the ac line source. Namely, undesired line current harmonics are generated in the distribution and transmission networks [5]. Thus, international standards, such as IEC61000-3-2, are defined to suppress the harmonic content of the main current [6].

Basically, an LED driver consists of a PFC circuit, followed by a $\mathrm{DC} / \mathrm{DC}$ converter that provides power to the load. This two-stage converter (Fig. 1) must satisfy the international standard of IEC61000-3-2 [7]. As the PFC circuit, a boost converter mainly is used. The regulation of inductor current through the boost converter improves both the total harmonic distortion (THD) and the power factor (PF) of the input current [8]. The DC/DC converter is used that performs both the function of maintaining the level of output voltage or current and isolating between the input and output of the converter. The used converter also is needed the high efficiency. Thus, to satisfy above requirements, researches in many resonant power converters

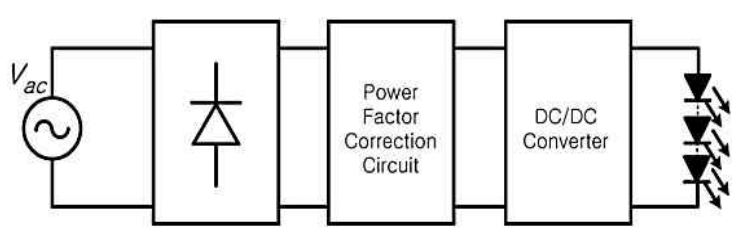

Fig. 1. The block diagram of conventional 2-stage LED converter 
have been carrying out. Specially, the LLC resonant converter frequently is chosen by lots of converter designers because of the merits of high power density, structural simplicity, miniaturization, etc $[9,10]$.

To overcome the disadvantages of two-stage converter, several types of single-stage converters were proposed to reduce switching devices, size, development and component cost [11]. However, these converters lead to poor efficiency and power density. In order to solve these problems, the explanation and analysis for single-stage resonant converters with high power density and efficiency was to be introduced [12]. Several types of single-stage resonant converters also were proposed [13, 14]. However, although these singlestage converters can be regulated through only one ICchip, more power switching devices and some of inductor must be needed or added. Thus, the size of converter may be larger than the two-stage converter. In another paper [15], a simple single-stage resonant converter was introduced. In this paper, components in the converter are reduced but the higher voltage stress is resulted in. Thus designer must be chosen expensive power switches for high voltage.

In the lighting market, most of the consumer wants to vary the brightness of the LED lamp for various purposes. This dimming function can be achieved by changing the reference figure [16]. However, this dimming technique needs a photocoupler. The photocoupler may be resulted in the slow operation and thus output current should be regulated as average values.

Output current can be figured out by the current value which flows in the primary side of the flyback converter. In the primary side of the flyback converter, a technique to dim output current by using at least a triac device was proposed [17, 18]. However, it has a serious problem that must be used in a low power application. Another way of dimming is pulse controlled dimming [19]. However, it needs extra control circuits.

To overcome the above-mentioned problem, this paper proposes a dimmable single-stage asymmetrical LLC resonant converter. The proposed converter result in the low voltage stress in power switches because of the low duty cycle of the lower switch. As the result of that, the power switches with the lower voltage level may be chosen by the circuit designer. Also, the associated passive components such as capacitors, inductor and transformer can be the lower voltage level. Thus the low-cost converter can be implemented. In addition, the proposed converter does not require any extra control circuits. In order to prove the validity and performance of the proposed converter, simulation and experimental works were performed by a $300 \mathrm{~W}$ prototype converter. The relationship between the switching frequency and output power is proved in this paper. Finally, simulation and experimental values are compared on the basis of the proposed theoretical background.

\section{Principle of the Proposed Converter}

The single-stage asymmetrical LLC resonant converter topology is depicted in Fig. 2. The filter inductor $\mathrm{L}_{\mathrm{f}}$, filter capacitor $\mathrm{C}_{\mathrm{f}}$ are a low pass filter to cut off the high frequency of the converter and Lin is a PFC inductor of the boost cell. Also, the switches $\mathrm{Q}_{1}, \mathrm{Q}_{2}$ operate at the asymmetrical duty ratio $0.8,0.2$, respectively. The bus

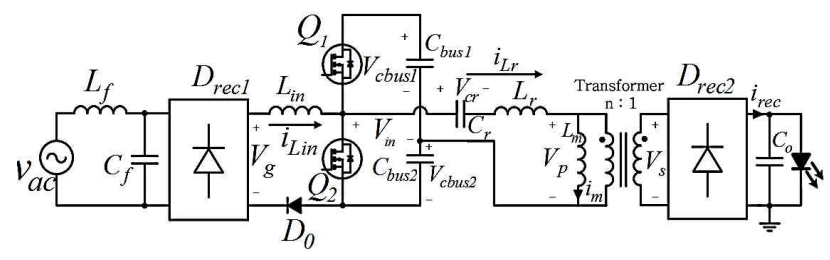

Fig. 2. Topology of the single-stage LLC resonant converter
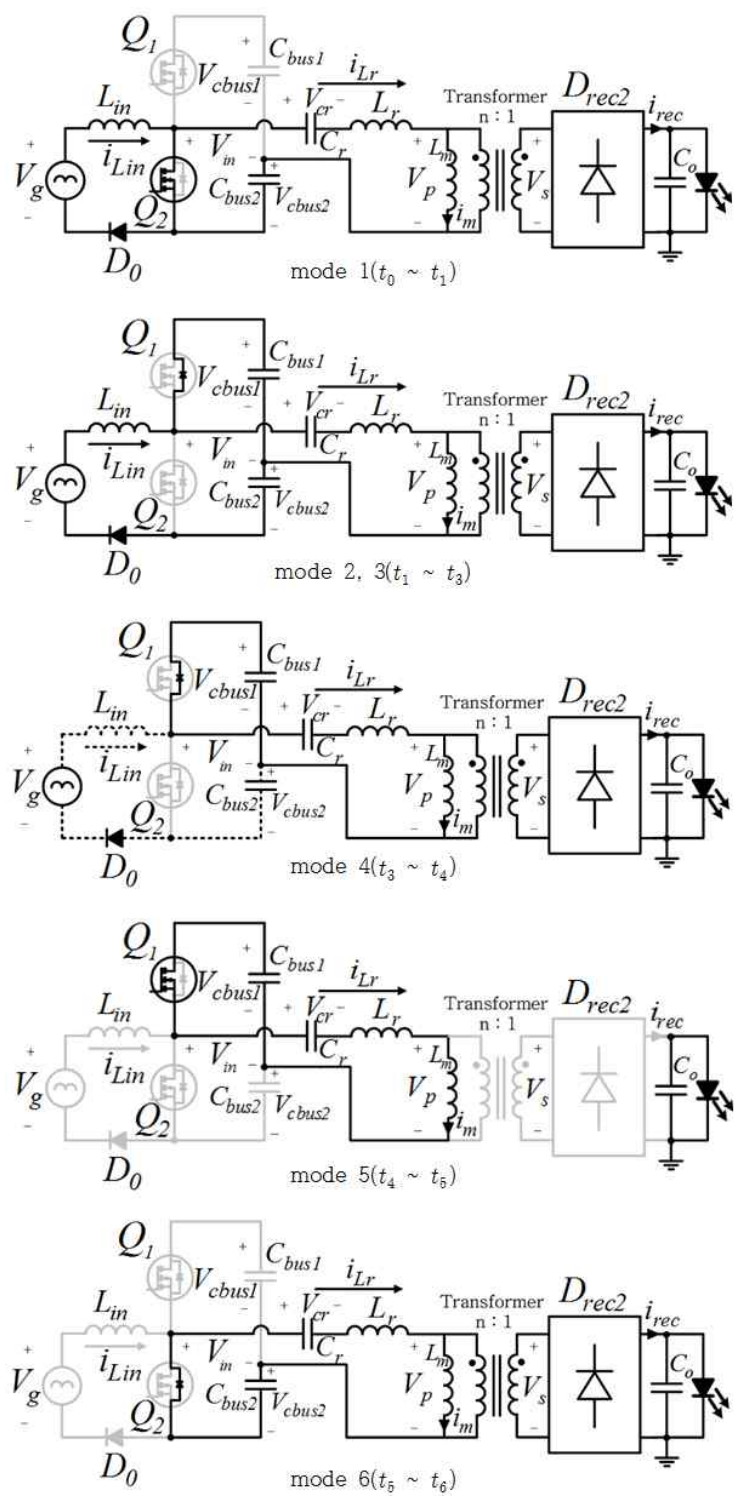

Fig. 3. Operation mode of the single-stage asymmetrical LLC resonant converter 
capacitors $\mathrm{C}_{\mathrm{bus}}, \mathrm{C}_{\mathrm{bus} 2}$ are large enough to minimize the input voltage ripples of the asymmetrical LLC resonant converter. The transformer is modeled as the magnetizing inductor $\mathrm{L}_{\mathrm{m}}$, the leakage inductor $\mathrm{L}_{\mathrm{r}}$, and an ideal transformer with a turn ratio of $n: 1$. The leakage inductor $\mathrm{L}_{\mathrm{r}}$ resonates with the resonant capacitor $\mathrm{C}_{\mathrm{r}}$ which is also block the dc voltage component of the input voltage in the asymmetrical LLC resonant converter. Thus the transformer is not saturated. The capacitance of the output capacitor is chosen as the enough value so that the converter output voltage is kept up with the constant. The specific parameters are mentioned in TABLE I.

Fig. 3 represents the detailed six switching modes for the converter operating cycle. Also, theoretical waveforms of the proposed converter are shown in Fig. 4.

A. Mode $1\left(\mathbf{t}_{\mathbf{0}} \sim \mathbf{t}_{1}\right)$ : The mode begins when $\mathrm{Q}_{2}$ is turned on at $\mathrm{t}=\mathrm{t}_{0}$ by the ZVS. The PFC inductor Lin is charged by the input voltage $V_{g}$. The PFC inductor current $\mathrm{i}_{\text {Lin }}$ flowing through the PFC inductor Lin increases linearly. At this moment, the magnetizing current $\mathrm{i}_{\mathrm{m}}$ also starts to flow through switch $\mathrm{Q}_{2}$. The input voltage $\mathrm{V}_{\text {in }}$ of the LLC resonant converter is reversed against the voltage $\mathrm{V}_{\text {cbus2 }}$. Thus, the magnetizing current $\mathrm{i}_{\mathrm{m}}$ is decreased and the energy of $\mathrm{C}_{\text {bus } 2}$ is transferred to the resonant part $\mathrm{L}_{\mathrm{r}}, \mathrm{C}_{\mathrm{r}}$. The output current of transformer becomes the difference between $i_{\text {Lr }}$ and $i_{\mathrm{m}}$.

B. Mode $2\left(t_{1} \sim t_{2}\right): Q_{2}$ is turned off at $t=t_{1}$ and then

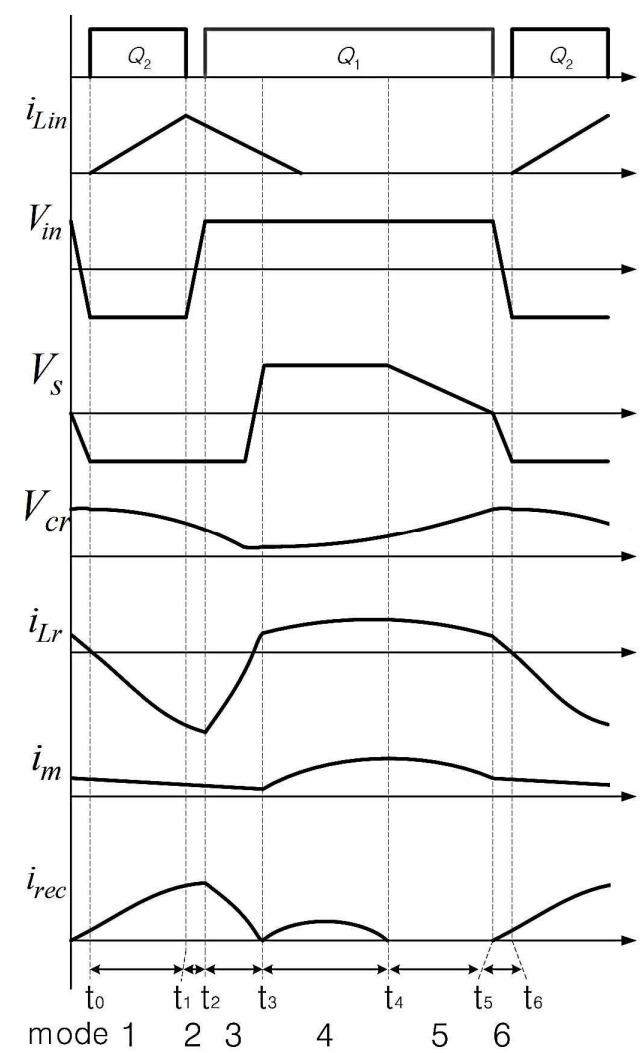

Fig. 4. Main waveform of the single-stage asymmetrical LLC resonant converter both switch $\mathrm{Q}_{1}$ and $\mathrm{Q}_{2}$ is turned off. At this time, the PFC inductor current $\mathrm{i}_{\text {Lin }}$ starts to fall because the inductor voltage becomes $V_{c}-V_{g}$. The bus capacitors $\mathrm{C}_{\text {bus1 }}, \mathrm{C}_{\text {bus } 2}$ are charged by the PFC inductor. At the same time, the magnetizing current $i_{m}$ flows through the diode of $Q_{1}$. The current leads to the condition of the zero voltage switching for $\mathrm{Q}_{1}$.

C. Mode $3\left(t_{2} \sim \mathbf{t}_{3}\right): Q_{1}$ is turn on at $t_{2}$ by the zero voltage switching. The input voltage of the LLC resonant converter is the voltage $\mathrm{V}_{\text {cbus1 }}$. At this moment, the voltage of the leakage inductor in the transformer is also changed. Hence, the leakage inductor current rises.

D. Mode $4\left(\mathbf{t}_{\mathbf{3}} \sim \mathbf{t}_{\mathbf{4}}\right)$ : When the direction of leakage inductor current is changed, the voltage of the magnetizing inductor $\mathrm{L}_{\mathrm{m}}$ becomes the positive voltage. Thus the magnetizing current is increased. During this time, the current of the PFC inductor is reached zero and this zero current is maintained until time $\mathrm{t}_{6}$. Hence, the power loss of the PFC inductor keeps up with the value of zero during this time. After the PFC inductor current is reached at zero, the magnetized current only is flowed into the switch $\mathrm{Q}_{1}$. This magnetized current is being continuously flowed because of the transformer with relatively small magnetizing inductance. Consequently, the condition of ZVS for $\mathrm{Q}_{2}$ can be obtained. At this interval, the leakage inductor resonates with resonant capacitor. The resonant current flows through the secondary side of the transformer.

E. mode $5\left(\mathbf{t}_{\mathbf{4}} \sim \mathbf{t}_{\mathbf{5}}\right)$ : At $\mathrm{t}=\mathrm{t}_{4}$, the secondary current of the transformer is approached zero. It means that the reverse recovery current of the rectifier diode $\mathrm{D}_{\text {rec2 } 2}$ is eliminated. Thus, the proposed converter has low switching loss.

F. mode $6\left(\mathbf{t}_{\mathbf{5}} \sim \mathbf{t}_{\mathbf{6}}\right)$ : At $\mathrm{t}=\mathrm{t}_{5}, \mathrm{Q}_{1}$ is turned off, the magnetizing current is flowed in $\mathrm{Q}_{2}$ 's diode. The condition of ZVS for $\mathrm{Q}_{2}$ is accomplished.

\section{Analysis of Voltage Conversion Ratio Versus Duty Ratio to Reduce Switch Voltage Stress in the DCM PFC}

Fig. 2 shows the single-stage LLC resonant converter. The single-stage LLC resonant converter consists of a boost-type PFC cell and the asymmetrical LLC resonant $\mathrm{dc} / \mathrm{dc}$ converter cell. The boost-type cell working in the DCM provides low input current harmonics without additional current-shaping controller in compliance with IEC61000-3-2 class C regulations [20].

The voltage stress of the switches is related to the dc-bus voltage $V_{c}$ by the Kirchhoff's voltage law (KVL), where $V_{c}=V_{c b u s l}+V_{c b u s 2}$ is the dc-bus voltage. Therefore, to reduce the voltage stress of switches, the dc-bus voltage reduction is necessary.

Defining the AC source voltage $v_{a c}(t)=V_{m} \sin w_{l} t$, the rectified output voltage is $V_{g}(t)=\left|V_{m} \sin w_{l} t\right|$, where $\mathrm{w}_{1}$ is the line angular frequency $\left(\mathrm{w}_{1}=2 \pi \mathrm{f}_{1}\right), \mathrm{f}_{1}$ is the line frequency, 


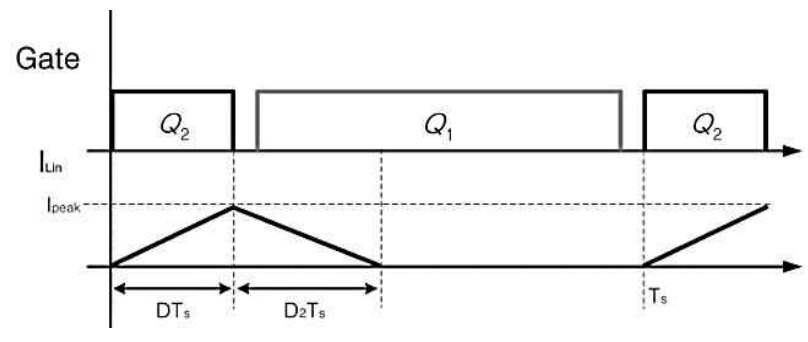

Fig. 5. Theoretical DCM inductor current waveform during the switching period

and $\mathrm{V}_{\mathrm{m}}$ is the peak line voltage.

Fig. 5 depicts the theoretical DCM inductor current wave form during the switching period. When the lower switch $\mathrm{Q}_{2}$ is turned on for the duration $\mathrm{DT}_{\mathrm{s}}$, the slope of inductor current is $V_{g} / L_{i n}$.

The slope of inductor current is $\left(V_{c}-V_{g}\right) / L_{\text {in }}$ when the lower switch is turned off and the diode are conducted during subinterval $\mathrm{D}_{2} \mathrm{~T}_{\mathrm{s}}$. The peak current $\mathrm{I}_{\text {peak.DTs }}$ and the peak current $\mathrm{I}_{\text {peak.D2Ts }}$ are, respectively

$$
\begin{gathered}
I_{\text {peak. } D T_{S}}=\left(V_{g} / L_{\text {in }}\right) \cdot D T_{s} \\
I_{\text {peak. } D_{2} T_{S}}=\left\{\left(V_{c}-V_{g}\right) / L_{\text {in }}\right\} \cdot D_{2} T_{s}
\end{gathered}
$$

Since the currents $I_{\text {peak.DTs }}$ and ${ }_{\text {Ipeak.D2Ts }}$ are the same, the voltage conversion ratio $M$ can be expressed as

$$
M=V_{c} / V_{g}=1+D / D_{2}
$$

However, another equation is needed to eliminate $D_{2}$ because of the unknown subinterval duty ratio $\mathrm{D}_{2}$ in equations (1) and (2). From the diode current $I_{D 1}$ of the upper switch, another equation can be obtained.

$$
I_{D 1}=\left(I_{\text {peak.DT }} \cdot D_{2}\right) / 2=V_{c} / R_{A L L C}
$$

Substitution of (1) into (4), one obtains

$$
M=V_{c} / V_{g}=D \cdot D_{2} T_{s} R_{A L L C} /\left(2 L_{\text {in }}\right)
$$

where, $\mathrm{R}_{\mathrm{ALLC}}$ is equivalent resistance of the asymmetrical LLC resonant converter.

Elimination of $\mathrm{D}_{2}$ from (3) and (5), and solution for the voltage conversion ratio $M(D, K)$, yields

$$
M(D, K)=V_{c} / V_{g}=\left\{1+\sqrt{1+\left(4 D^{2} / K\right)}\right\} / 2
$$

where, $K=2 L_{\text {in }} /\left(R_{A L L C} \cdot T_{s}\right)$.

According to (6), the voltage conversion ratio versus the duty ratio of the lower switch $\mathrm{Q}_{2}$ could be derived, and these characteristics are plotted in Fig. 6. It is assumed the equivalent resistance of the asymmetrical LLC resonant converter is constant. It can be seen that the characteristics of the DCM boost converter becomes be nearly linear. That

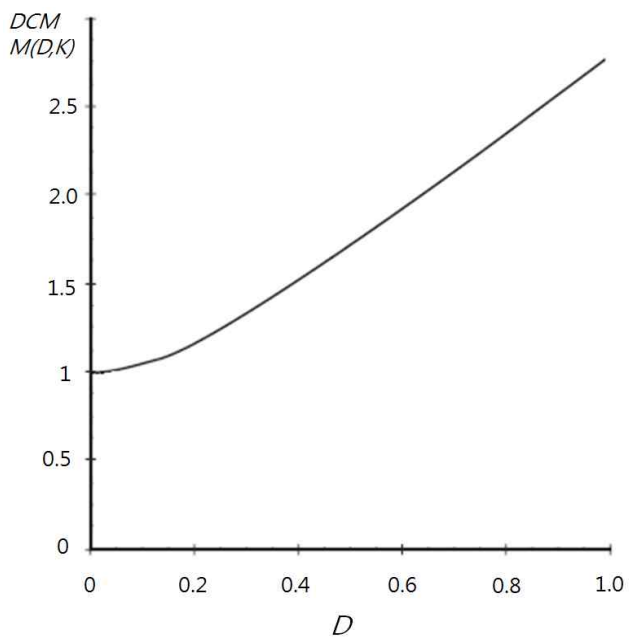

Fig. 6. The voltage ratio versus the duty ratio of the lower switch Q2 in the DCM

means it can be reduced voltage conversion ratio when operated at low duty cycle [21]. The voltage stress across the power switches is the dc bus voltage $\mathrm{V}_{\mathrm{c}}$. Therefore, power switches of converter have low voltage stress at the low duty ratio of the lower switch $\mathrm{Q}_{2}$.

\section{Analysis of Dimming Method Through Frequency Control}

To reduce the voltage stress of the switches, the low duty ratio of the lower switch $\mathrm{Q}_{2}$ should be designed and fixed. To dim of the LED lighting by the control of the switching frequency, the analysis for the average output voltage of the primary bridge diode and the average current of the PFC inductor per a period $T_{1}$ (a reciprocal of the line frequency) is developed in this chapter.

The average value of $\mathrm{V}_{\mathrm{g}}$ can be obtained [22].

$$
\begin{aligned}
V_{g, a v g_{-} T_{l}} & =\left(2 / T_{l}\right) \cdot \int_{0}^{T_{l} / 2} V_{m} \sin w_{l} t d t \\
& =2 V_{m} / \pi
\end{aligned}
$$

To obtain the average current of the inductor during a period $\mathrm{T}_{1}$, two steps are needed. First, using the triangle area formula, the average current of the PFC inductor current during a switching period could be obtained as follows

$$
i_{\text {Lin.avg_Ts }}=\left(D+D_{2}\right) I_{\text {peak. } D T_{S}} / 2
$$

Substitution of (1) and (3) into (8) leads to

$$
i_{\text {Lin.avg_Ts }}=\left\{D^{2} V_{c} /\left(2 L_{\text {in }} f_{s}\right)\right\} \cdot V_{g} /\left(V_{c}-V_{g}\right)
$$

Rewriting the equation (9) and using $V_{g}(t)=\left|V_{m} \sin w_{l} t\right|$, 


$$
\begin{gathered}
i_{\text {Lin.avg_Ts }}=\left\{D^{2} V_{c} /\left(2 L_{i n} f_{s}\right)\right\} \cdot\left|V_{m} \sin w_{l} t\right| / \\
\left(V_{c}-\left|V_{m} \sin w_{l} t\right|\right)
\end{gathered}
$$

To derive the average current during the period $T_{1}$ of the PFC inductor, integration leads to

$$
\begin{aligned}
& i_{\text {Lin.avg_ } T_{l}}=\frac{T_{l}}{2} \int_{0}^{T_{l} / 2}\left\{D^{2} V_{c} /\left(2 L_{\text {in }} f_{s}\right)\right\} . \\
& \left|\alpha \sin w_{l} t\right| /\left(1-\left|\alpha \sin w_{l} t\right|\right) d t \\
& \quad=\frac{D^{2} V_{c}}{T_{l} L_{\text {in }} f_{s}} \cdot\left\{\frac{\pi}{w_{l} \sqrt{1-\alpha^{2}}}-\frac{T_{l}}{2}+\frac{2 \tan ^{-1}\left(\alpha / \sqrt{1-\alpha^{2}}\right)}{w_{l} \sqrt{1-\alpha^{2}}}\right\}
\end{aligned}
$$

where, $\alpha=V_{m} / V_{c}$.

Solution for the input power then leads to

$$
P_{\text {in }}=V_{g_{\text {.avg }} T_{l}} \times I_{\text {Lin.avg }_{-} T_{l}}
$$

Substitution of (7) and (12) into (13) result in

$$
P_{\text {in }}=\frac{2 V_{m} D^{2} V_{c}}{\pi T_{l} L_{\text {in }} f_{s}} \cdot\left\{\frac{\pi}{w_{l} \sqrt{1-\alpha^{2}}}-\frac{T_{l}}{2}+\frac{2 \tan ^{-1}\left(\alpha / \sqrt{1-\alpha^{2}}\right)}{w_{l} \sqrt{1-\alpha^{2}}}\right\}
$$

From (14), the input power is in inverse proportion to the switching frequency. Therefore, the brightness of the LED lamp can be controlled through the variation of the switching frequency. A control law for the LED dimming is obtained by (14).

Finally, Fig. 7 shows a block diagram of the controller. The controller is implemented by (14). For the dimming of the LED lighting, PWM signals having the frequency corresponding to the desired output are artificially generated from the microcontroller and transferred to the gate terminal of the switching device. Since the controller is simple, it can be easily implemented using most modern micro-controllers, digital signal processors and analog devices.

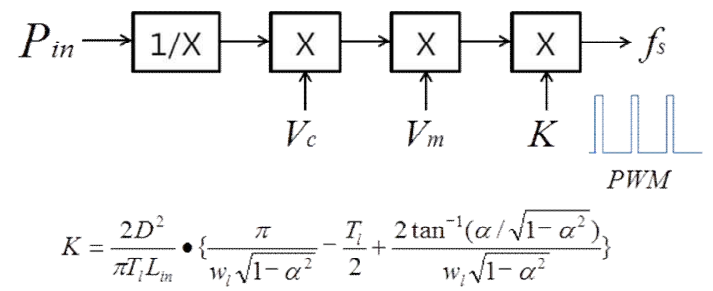

Fig. 7. A block diagram of the controller

\section{The Verification of the Proposed Converter}

To verify the feasibility of the proposed converter, simulation and experimental results from a $300 \mathrm{~W}$ prototype are provided. The parameters of the prototype are given in
Table 1. The parameter of the proposed converter

\begin{tabular}{c|c|c}
\hline Parameter & Symbol & Value \\
\hline Switching frequency range & $\boldsymbol{f}_{\boldsymbol{s}}$ & $\mathbf{8 0 \sim 2 0 0 ( \mathbf { k H z } )}$ \\
\hline Input filter inductor & $L_{f}$ & $660(\mathrm{uH})$ \\
\hline Input filter capacitor & $C_{f}$ & $570(\mathrm{nF})$ \\
\hline Input inductor & $L_{\text {in }}$ & $85(\mathrm{uH})$ \\
\hline Bus capacitor1,2 & $C_{\text {bus } l, 2}$ & $820(\mathrm{uF})$ \\
\hline Resonant capacitor & $C_{r}$ & $47(\mathrm{nF})$ \\
\hline $\begin{array}{c}\text { Resonant inductor } \\
\text { (leakage inductor of transformer) }\end{array}$ & $L_{r}$ & $101(\mathrm{uH})$ \\
\hline Magnetizing inductor of transformer & $L_{m}$ & $902(\mathrm{uH})$ \\
\hline Turns ratio of transformer & $n$ & 3.1 \\
\hline Output capacitor & $C_{o}$ & $470(\mathrm{uF})$ \\
\hline Maximum LED voltage & $V_{L E D}$ & $58(\mathrm{~V})$ \\
\hline Maximum LED current & $I_{L E D}$ & $5.4(\mathrm{~A})$ \\
\hline
\end{tabular}

Table 1.

\subsection{The simulation results}

The proposed converter was simulated using the POWERSIM package. The input voltage and the current are shown in Fig. 8 that the horizontal time axis is $10 \mathrm{msec}$ per a division. Also, the measured line current waveform has the power factor of 0.988 and total harmonic distortion of $15.56 \%$. The input current $\mathrm{I}_{\mathrm{ac}}$ contains third harmonics because of ratio of the input voltage and the output voltage of the boost type cell [23].
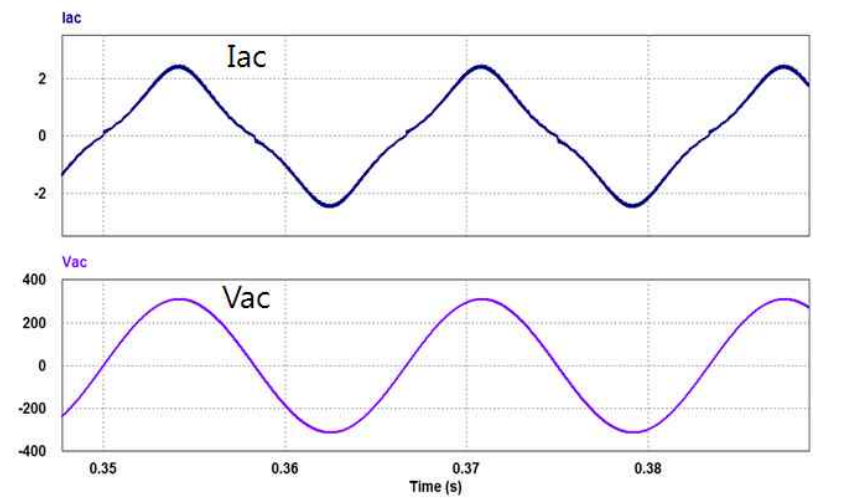

Fig. 8. The simulation waveforms of the input voltage, current of the converter under the full load

Fig. 9 shows the output voltages of the DCM PFC boost cell under the full load. In the proposed converter, the average bus voltage is about $500 \mathrm{~V}$. However, the average bus voltage conventional converter is about $820 \mathrm{~V}$. Thus, the proposed converter has the lower voltage stress across switching devices.

\subsection{The experimental results}

The output power is rated at $300 \mathrm{~W}$, the input voltage is $220 \mathrm{~V}_{\mathrm{rms}}$ and the load is the LED, the steady-state driving parameters of which are $150 \mathrm{~mA} / 9.5 \mathrm{~V}$. A LED module consists of 9 LED rings and 6 LEDs per rings. Four LED 
The Dimmable Single-stage Asymmetrical LLC Resonant LED Driver with Low Voltage Stress Across Switching Devices

Vc of the conventional converter

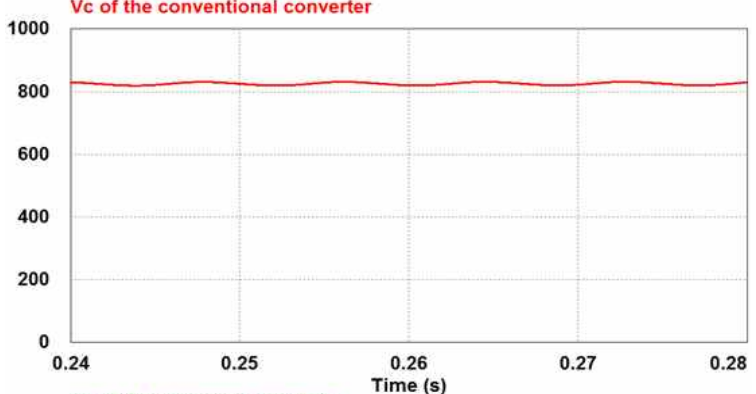

$\mathrm{Vc}$ of the proposed converter

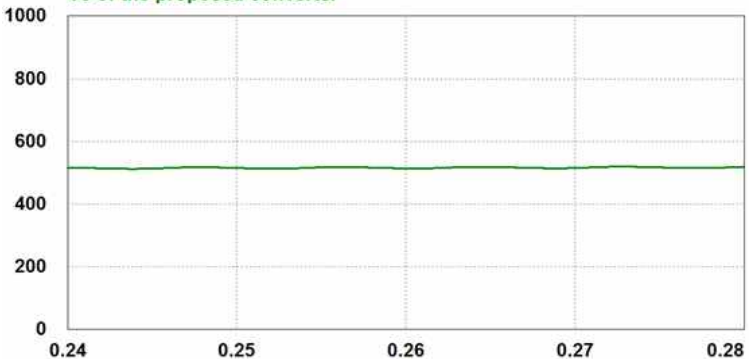

Fig. 9. The simulation waveforms of the bus capacitors voltage $\mathrm{V}_{\mathrm{c}}$ of the converter under the full load

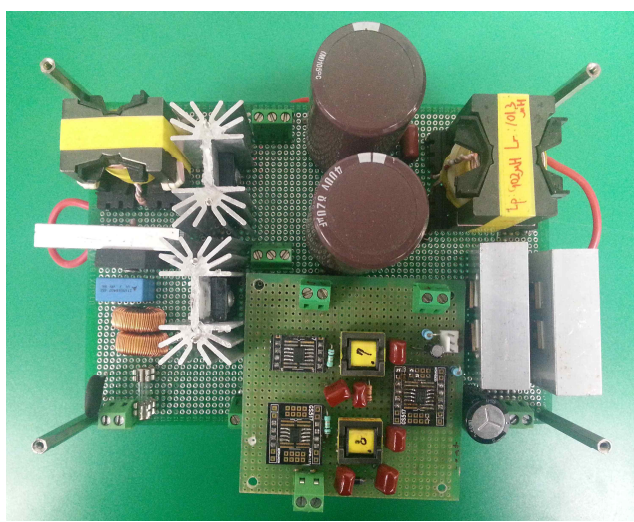

Fig. 10. The prototype of the proposed converter

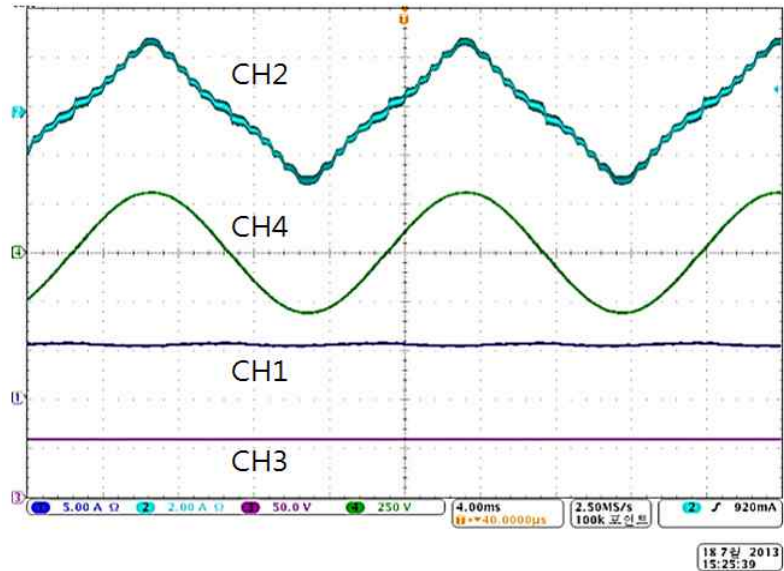

Fig. 11. Experimental waveforms under the full load $\mathrm{CH} 1$ : LED current $\mathrm{I}_{\mathrm{LED}}(5 \mathrm{~A} /$ div $), \mathrm{CH} 2$ : input current $\mathrm{i}_{\mathrm{ac}}$ (2A/div), CH3: LED voltage $\mathrm{V}_{\text {LED }}(50 \mathrm{~V} / \mathrm{div})$, $\mathrm{CH} 4$ : input voltage $\left.\mathrm{V}_{\mathrm{ac}}(250 \mathrm{~V} / \mathrm{div})\right)$ modules are used as the load of the converter [24].

A prototype for the proposed system has been built as shown in Fig. 10. In the proposed converter, the leakage inductance for the resonance inductor is included in the transformer to reduce passive components.

Fig. 11 and 12 are the currents and voltages of the converter with the LED load under the full load and half load, respectively. Accordingly, the waveforms of the LED current are varied by the switching frequency adjustment. Also, the phenomenon of flicker in the LED lamp does not observed through the experimental works because of the almost constant LED current without ripples.

In Fig. 13, the bus voltage waveform of the DCM PFC boost cell under the full load is shown. It can be seen that the average voltage of sum of bus capacitors $\mathrm{C}_{\text {bus } 1}, \mathrm{C}_{\text {bus } 2}$ is about $500 \mathrm{~V}$. It means voltage stress of power switches is approximately $500 \mathrm{~V}$.

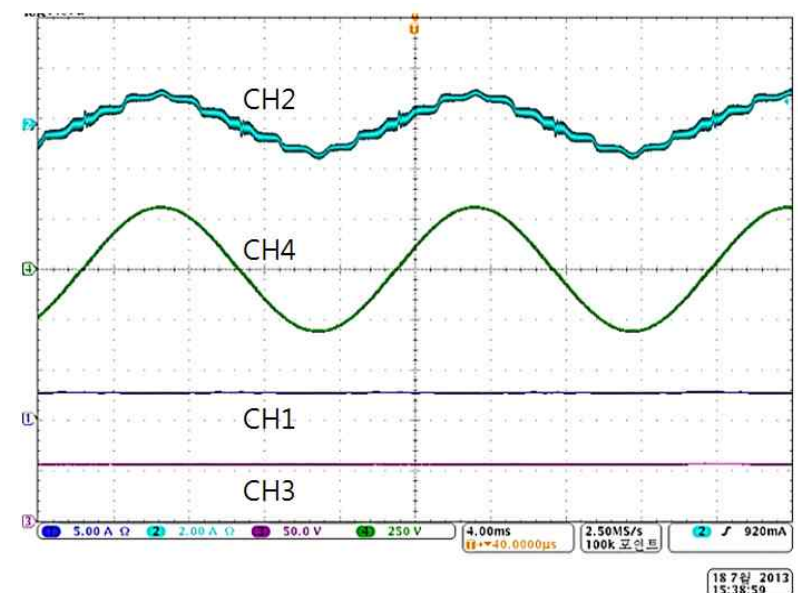

Fig. 12. Experimental waveforms under the half load. CH1: LED current $\mathrm{I}_{\mathrm{LED}}(5 \mathrm{~A} / \mathrm{div}), \mathrm{CH} 2$ : input current $\mathrm{i}_{\mathrm{ac}}(2 \mathrm{~A} / \mathrm{div}), \mathrm{CH} 3$ : LED voltage $\mathrm{V}_{\mathrm{LED}}$ (50V/div), CH4: input voltage $\mathrm{V}_{\text {ac }}(250 \mathrm{~V} / \mathrm{div})$

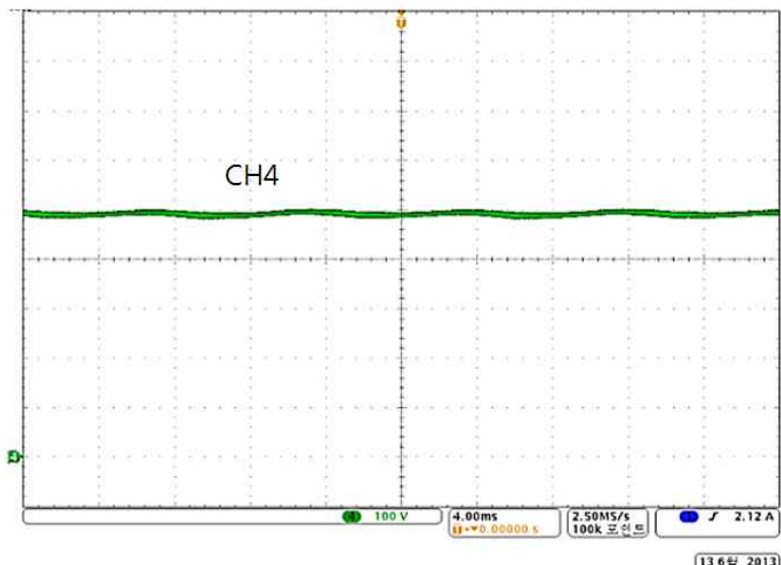

Fig. 13. Experimental waveform of the dc bus voltage under the full load CH4: dc bus voltage $\mathrm{V}_{\mathrm{c}}(100 \mathrm{~V} /$ div) 
Fig. 14 and 15 shows the drain-to-source voltage of primary switches $\mathrm{Q}_{1}$ and $\mathrm{Q}_{2}$. It can be shown that the ZVS condition improve the overall conversion efficiency.

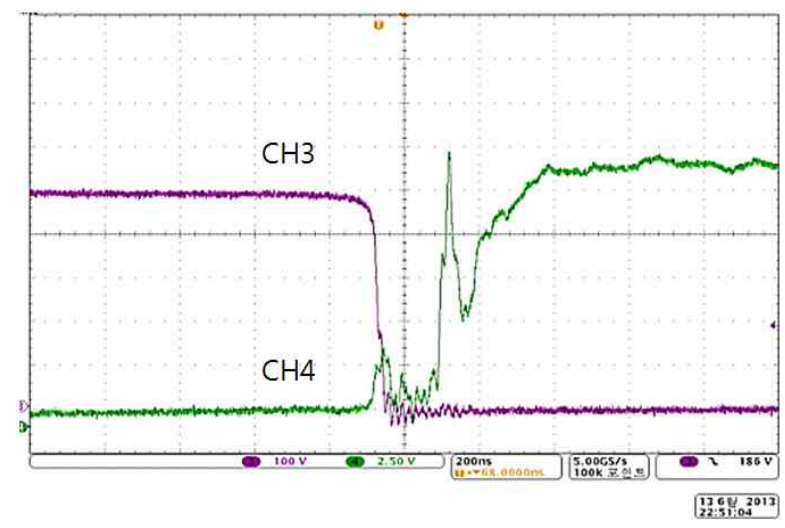

Fig. 14. The ZVS waveforms of the top switch under the full load (CH3: Top switch voltage, $\mathrm{V}_{\text {top.ds }}(100 \mathrm{~V} /$ div), $\mathrm{CH} 4$ : Top switch gate voltage $\mathrm{V}_{\text {top.gs }}(2.5 \mathrm{~V} /$ div))

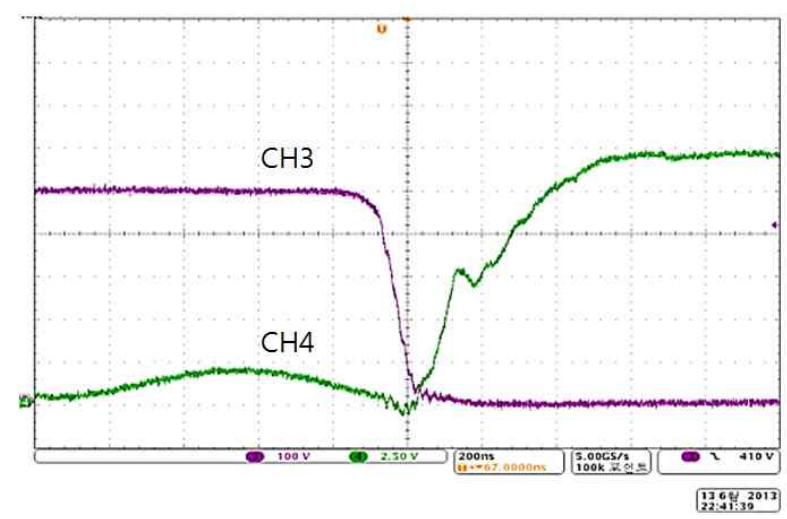

Fig. 15. The ZVS waveforms of the switch under the full load. (CH3: Bottom switch voltage, $\mathrm{V}_{\text {bottom.ds }}(100 \mathrm{~V} /$ div), $\mathrm{CH} 4$ : Bottom switch gate voltage $\mathrm{V}_{\text {bottom.gs }}$ $(2.5 \mathrm{~V} / \mathrm{div}))$

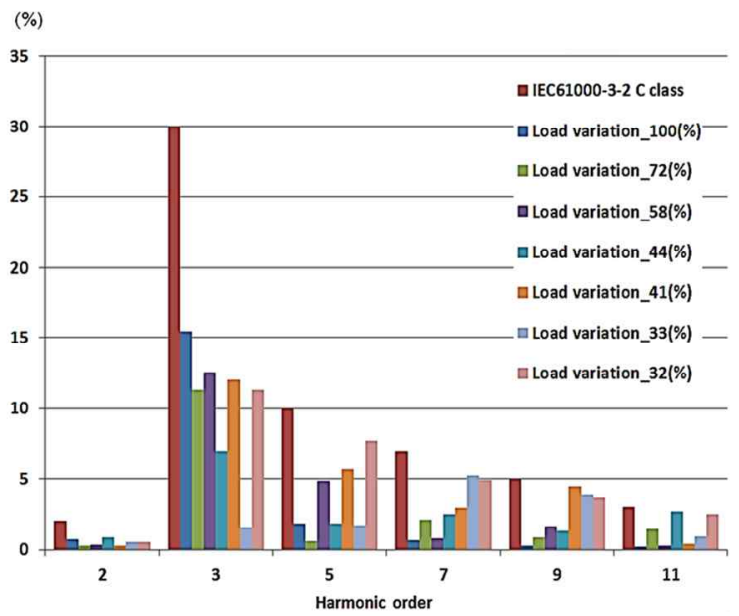

Fig. 16. The harmonics spectrum of the input current of the proposed converter under the load variation
Fig. 16 shows the harmonics spectrums of the input current at $\mathrm{v}_{\mathrm{ac}}=220 \mathrm{Vrms}$ under the load variation. Each measured harmonic component meets the IEC61000-3-2 Class $\mathrm{C}$ requirement, as shown in Fig. 16. The THDs are $19.07 \%$ (at load variation $100 \%$ ), $16.51 \%$ (at $72 \%$ ), $20.34 \%$ (at $58 \%$ ), $19.07 \%$ (at $44 \%$ ), $25.71 \%$ (at $41 \%$ ), $25.71 \%$ (at $33 \%$ ) and $25.71 \%$ (at $32 \%$ ), respectively.

The bus voltage of the DCM PFC boost cell, power factor and conversion efficiency for the laboratory prototype are measured and shown in Fig. 17. The bus voltage of DCM PFC boost cell is measured about $500 \mathrm{~V}$ under the full load. Also, almost unity power factor is obtained under various load conditions.

The highest conversion efficiency is measured about $87 \%$ at full load.

Fig. 18 is the curve of the output power versus the applied switching frequencies and also exhibits the theoretically

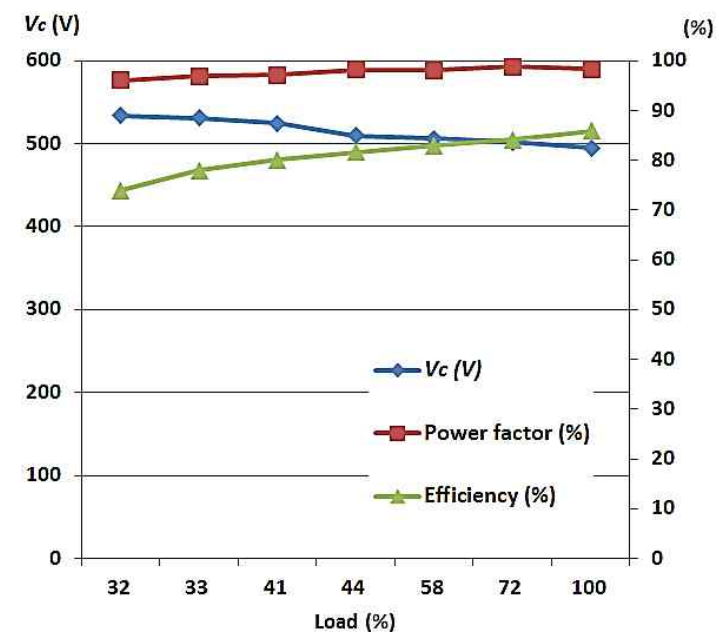

Fig. 17. The bus voltage $V_{c}$, power factor and efficiency under load variation

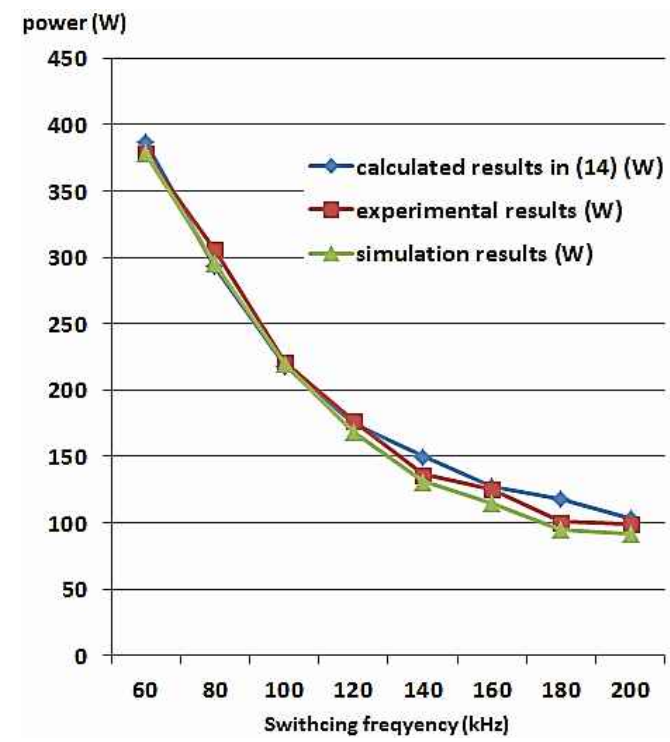

Fig. 18. The curve of the output power versus the applied switching frequencies 
calculated results in (14), the simulated results by the simulation tool and the experimental results. These results show that the verification of dimming method controlled by the switching frequency is proved.

\section{Conclusion}

In this paper, a dimmable single-stage asymmetrical LLC resonant converter was proposed. The proposed converter result in the low voltage stress in power switches because of the low duty cycle of the lower switch. For the dimming control of the LED lamp, the effective input power was analyzed through the terms of both the input inductor current and the output voltage of the rectifier diode. A related equation for the switching frequency was induced.

The proposed converter has been verified through the actual experimental works. Furthermore, the unit power factor was achieved and the required standard of the IEC61000-3-2 Class $C$ was satisfied.

\section{Acknowledgements}

This work was supported by Inha University Research Grant.

\section{References}

[1] Eung-Seok Kim and Cherl-Jin Kim, "Sliding Mode Current Controller Design for Power LEDs" Journal of Electrical Engineering \& Technology, Vol. 6, No. 1, pp. 104-110, 2011.

[2] Toshihiko Komine, and Masao Nakagawa, "Fundamental Analysis for Visible-Light Communication System using LED Lights," in Proc. IEEE Trans. Consumer Electron., vol. 50, no. 1, pp. 100-107, Feb. 2004.

[3] Shih-Mim Liu, Ching-Feng Chen, and Kuang-Chung Chou, "The Design and implementation of a LowCost 360-degree Color LED Display System," in Proc. IEEE Trans. Consumer Electron., vol. 57, no. 2, pp. 289-296, May. 2011.

[4] Jorge Garcia, Antonio J. Calleja, Emilio Lopez Corominas, David Gacio Vaquero, and Lidia Campa, "Interleaved Buck Converter for Fast PWM Dimming of High-Brightness LEDs," in Proc. IEEE Trans. Power Electron., vol. 26, no. 9, pp. 2627-2636, Sept. 2011.

[5] Richard C. dorf and James A. Svoboda, Introduction to Electric circuits, $7^{\text {th }}$ ed., John Wiley \& Sons, Inc., 2006, pp. 509-511.

[6] IEC Std. 61000-3-2. Electromagnetic compatibility. Part 3: Limits. Section 2: Limits for harmonic current emissions (equipment input current $\leq 16 \mathrm{~A}$ per phase), 1995.

[7] Ashish Shrivastava, and Bhim Singh, "LLC Series Resonant Converter Based LED Lamp Driver with ZVS," in Proc. IEEE Fifth Power India conference, Murthal, INDIA, pp. 1-5, Dec. 2012.

[8] Oscar Garcia, Jose A. Cobos, Roberto Prieto, Pedro Alou, and Javier Uceda, "Single Phase Power Factor Correction: A Survey," in Proc. IEEE Trans. Power Electron., vol. 18, no. 3, pp. 749-755, May. 2003.

[9] S. De Simone, C. Adragna, C. Spini, and G. Gattavari, "Design-oriented steady state analysis of LLC resonant converter based on FHA," in Proc. International Symposium on Power Electronics, Taormina, Hawaii, pp. 200-207, May. 2006.

[10] Junming Zhang, Jianfeng Wang, Guoxing Zhang, and Zhaoming Qian, "A Hybrid Driving Scheme for FullBridge Synchronous Rectifier in LLC Resonant Converter," in Proc. IEEE Trans. Power Electron., vol. 27, no. 11, pp. 4549-4561, Nov. 2012.

[11] R. Kalpana, Bhim Singh and G. Bhuvaneswari, "Direct Single-stage Power Converter with Power Factor Improvement for Switched Mode Power Supply" Journal of Electrical Engineering \& Technology, Vol. 5, No. 3, pp. 468-476, 2010

[12] Dara L. O'Sullivan, Michael G. Egan, and Michael J. Willers, "A Family of Single-Stage Resonant AC/DC Converters With PFC," in Proc. IEEE Trans. Power Electron., vol. 24, no. 2, pp. 398-408, Feb. 2009.

[13] H. -L. Do, and B.-H. Kwon, "Single-stage asymmetrical PWM AC-DC converter with high power factor," in Proc. IEE Proceedings-. Electric Power Appl., vol. 149, no. 1, pp. 1-8, Jan. 2002.

[14] Chun-An Cheng, and Chun-Hsien Yen, "A SingleStage Driver for High Power LEDs," in Proc. $\sigma^{\text {th }}$ IEEE Conference on Industrial Electron. and Appl., Beijing, CHINA, pp. 2666-2671, Jun. 2011.

[15] C.M. Lai, and K.K. Shyu, "A single-stage AC/DC converter based on zero voltage switching LLC resonant topology," in Proc. IET Electric Power Appl. vol. 1, no. 5, pp. 743-752, Sept. 2007.

[16] W.A. Rodrigues, L.M.F. Morais, P.F. Donoso-Garcia, and S.I. Seleme JR, "Comparative Analysis of Power LEDS Dimming Methods," in Proc. Brazilian Power Electron. Conference, Praiamar, BRAZIL, pp. 373383, Sept. 2011.

[17] Junming Zhang, Ting Jiang, Hulong Zeng, and Xinke $\mathrm{Wu}$, "Primary side feedforward control for TRIAC dimmable light emitting diode driver with Constant Power," in Proc. IET Power Electron., vol. 6, no. 3, pp. 572-580, March. 2013.

[18] Junming Zhang, Hulong Zeng, and Ting Jiang, "A Primary-Side Control Scheme for High-Power-Factor LED Driver With TRIAC Dimming Capability," in Proc. IEEE Trans. Power Electron., vol. 27, no. 11, pp. 4619-4629, Nov. 2012. 
[19] Zhen Liu, Wen-Jiang Wang, Hai-Cheng Wei, and Chun-Liang Liu, "A Novel ZVS Double Switch Flyback Inverter and Pulse Controlled Dimming Methods for Flat DBD Lamp," in Proc. IEEE Trans. Consumer Electron., vol. 57, no. 3, pp. 995-1002, Aug. 2011.

[20] Xiaotian Zhang, and Joseph W. Spencer, "Analysis of Boost Converters Operation in the Discontinuous Conduction Mode", in Proc. IEEE Trans. Power Electron., vol. 26, no. 12, pp. 3621-3628, Dec. 2011.

[21] Robert W. Erickson and Dragan Maksimovic, Fundamentals of Power Electronics, $2^{\text {nd }}$ ed., Kluwer Academic Publishers, 2001, pp. 124-125.

[22] N. Mohan, Tore M. Undeland, and William P. Robbins, Power Electronics, $3^{\text {rd }}$ ed., John Wiley \& Sons, Inc., 2003, pp. 82-87.

[23] Kwang-Hwa Liu, and Yung-Lin Lin, "Current waveform distortion in power factor correction circuits employing discontinuous-mode boost converters", PFSC '89 Record. 20 ${ }^{\text {th }}$ Annual IEEE Power Electron. Specialists Conference, Milwaukee, WI, pp. 825-829, Jun. 1989.

[24] Samsung LED, "LED Street Light Module: STOSEW 150900002 SSTD”, 2010.

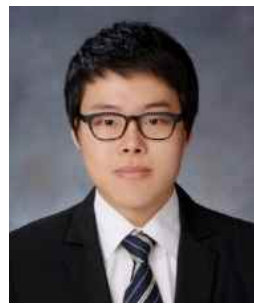

Seong-Ju Kim He was born in Yeosu, Korea, in 1987. He received the B.S. and M.S. degrees in Electrical Engineering from Inha University, Incheon, Korea, in 2012 and 2014 respectively. Since 2014 , he is currently working LG Electronics, Korea. His main research interests are $\mathrm{AC} / \mathrm{DC}$ converters and resonant converters.

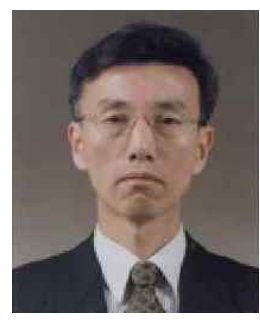

Young-Seok Kim He received the B.S. degree in Electrical Engineering from Inha University, Korea, in 1977 and his M.S and Ph.D degrees in Electrical Engineering from Nagoya University, Japan in 1984 and 1987, respectively. In 1989, he joined Inha University in Korea where he is currently a Professor in Dept. of Electrical Engineering. His research areas are Motor Drives, Electric Vehicle, Power Converters and Renewable Energy.

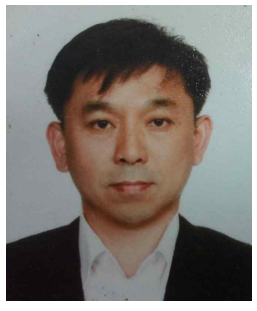

Choon-Taek Kim He received the B.S. and M.S. degrees in Electrical Engineering department from Inha University, Incheon, Korea, in 1991 and 1993, respectively. He had developed Electric Control System for industrial vehicle in Doosan Infracore from 1994 to 2015. $\mathrm{He}$ is currently working toward the Ph.D. degree in electrical engineering at Inha University since 2013. His research interests are power-factor-correction converters, LC resonant filters and high-frequency softswitching techniques.

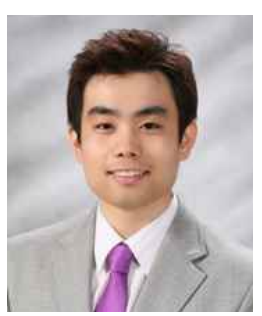

Joon-Min Lee He received the B.S. and M.S. degree in electrical engineering from Inha University, Incheon, Korea, in 2009 and 2011. From 2011 to 2012, He was a Researcher with the LSIS R\&D Center. Since 2013, He has been a Ph.D candicate in Dept. of Electrical Engineering, Inha University. His research areas are Motor Drives, Electric Vehicle and Renewable Energy.

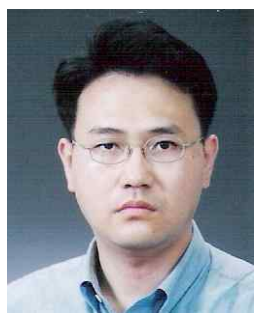

Jae-Du La He received Ph.D degree in electrical engineering from University of Birmingham, United Kingdom in 2008. He is currently an Associate Professor with the Department of Electrical Information, Inha Technical College, Incheon, Korea. His research areas are Power Converters and Motor Drives using microcontrollers, Battery Chargers, Power Supplies for Arc and UV LED lamps, etc. 